\title{
Retrospective study on assessment of risk for gestational diabetes using fetal medicine foundation's gestational diabetes risk assessment calculator in a tertiary care hospital in coastal Karnataka, India
}

\author{
Pradeep Ganiga, Vivek V. Subhash*
}

Department of Obstetrics and Gynecology, A. J. Institute of Medical Sciences, Mangaluru, Karnataka, India

Received: 07 February 2020

Accepted: 17 February 2020

*Correspondence:

Dr. Vivek V. Subhash,

E-mail: vivekvs1992@gmail.com

Copyright: () the author(s), publisher and licensee Medip Academy. This is an open-access article distributed under the terms of the Creative Commons Attribution Non-Commercial License, which permits unrestricted non-commercial use, distribution, and reproduction in any medium, provided the original work is properly cited.

\begin{abstract}
Background: Gestational diabetes is defined as impaired glucose tolerance with onset or first recognition during pregnancy. Undiagnosed or inadequately treated gestational diabetes can lead to significant maternal and fetal complications. Even though there are guidelines for diagnosis of GDM (gestational diabetes mellitus) by the Government of India, there is poor penetration of the implementation throughout the nation.

Methods: The study was conducted in A. J. Institute of Medical Sciences between April to June 2019. 56 patients were evaluated with the fetal medicine foundation GDM risk calculator to assess the risk for gestational diabetes in a retrospective approach.

Results: Incidence of GDM in the study was $15.9 \%$. At a cut-off of $1 / 80$, the calculator predicted increased risk for 37 out of 56 patients. There was a sensitivity of $91.6 \%$ and specificity of $63.6 \%$ with a negative predictive value of $96.5 \%$ and positive predictive value of $29.5 \%$. there was a false positive rate of $43.2 \%$.

Conclusions: The fetal medicine foundation GDM risk calculator will prove to be an invaluable tool to predict high risk patients who need closer monitoring of blood glucose into the third trimester.
\end{abstract}

Keywords: Fetal medicine foundation, Gestational diabetes, Risk calculator

\section{INTRODUCTION}

Gestational diabetes (GDM) is defined as impaired glucose tolerance with onset or first recognition during pregnancy. Undiagnosed or inadequately treated gestational diabetes can lead to significant maternal and fetal complications. ${ }^{1}$

Normal pregnancy is commonly associated with insulin resistance like that found in type 2 diabetes. Physiological resistance to insulin action during pregnancy becomes apparent in the second trimester, and this progresses gradually to term. The increased insulin resistance facilitates transplacental transfer of glucose to the fetus, which in turn stimulates fetal insulin secretion, and insulin acts as an essential growth hormone. ${ }^{2}$ The excessive insulin in turn predisposes more accumulation of carbohydrates into the fetus, leading to large for gestational age or macrosomic babies. During delivery, macrosomia increases the risk of shoulder dystocia, clavicle fractures and brachial plexus injury and increases the rate of admissions to the neonatal intensive care unit. ${ }^{3}$

In India alone, GDM complicates nearly 4 million pregnancies annually, representing large subset of population at high risk for adverse perinatal morbidity and mortality if left inappropriately managed. ${ }^{4}$ GDM is associated with increased rate of neonatal hypoglycaemia, preterm birth, hyperbilirubinemia, hypocalcemia, polycythemia, childhood obesity, neuropsychological disturbance, anomalies like anencephaly, spina bifida, renal agenesis, TGV, VSD, 
single umbilical artery, sacral agenesis. Women with GDM demonstrated high rate of caesarean section and future risk of diabetes. Women with gestational diabetes and their offspring are also at an increased risk of developing Type 2 diabetes later in life. In India rates of GDM are estimated to be 10 to $14.3 \% .^{1}$ Despite government of India mandate to screen all Indian pregnant women for GDM as a part of routine antenatal package according to national operational guidelines, its real operationalization at primary health care level is still unclear. In a study in Bangalore less than half of government doctors (44\%) employed oral glucose tolerance test (OGTT) to diagnose GDM with mere $74 \%$ prescribing recommended $75 \mathrm{~g}$ glucose. Few utilized $50 \mathrm{~g}$ $(18 \%)$ and $100 \mathrm{~g}(8 \%)$ glucose for performing OGTT. Most doctors were utilizing other screening tests like random blood glucose (46\%), fasting plasma glucose $(18 \%)$, and postprandial blood glucose (12\%) for diagnosing GDM, outside recommended national guidelines. ${ }^{4}$ The Government of India guidelines have been compared with other standardised screening and diagnostic criteria in Table 1.

Table 1: Comparison of various guidelines for detecting gestational diabetes.

\begin{tabular}{|llllll|}
\hline Guidelines & FBS (mg/dl) & $\begin{array}{l}\text { Glucose } \\
\text { load }\end{array}$ & $\begin{array}{l}\text { 1-hour blood } \\
\text { sugar (mg/dl) }\end{array}$ & $\begin{array}{l}\text { 2-hour blood } \\
\text { sugar (mg/dl) }\end{array}$ & $\begin{array}{l}\text { 3-hour blood } \\
\text { sugar (mg/dl) }\end{array}$ \\
\hline WHO $^{6}$ & $>/=126$ & $75 \mathrm{~g}$ & Not required & $>/=140$ & Not required \\
\hline ACOG $^{7}$ & $>/=95$ & $100 \mathrm{~g}$ & $>/=180$ & $>/=155$ & $>/=140$ \\
\hline Canadian diabetes association $^{8}$ & $>/=95$ & $75 \mathrm{~g}$ & $>/=191$ & $>/=160$ & Not required \\
\hline IADPSG $^{9}$ & $>/=92$ & $75 \mathrm{~g}$ & $>/=180$ & $>/=153$ & Not required \\
\hline DIPSI $^{10}$ & Not required & $75 \mathrm{~g}$ & Not required & $>/=140$ & Not required \\
\hline
\end{tabular}

The fetal medicine foundation's gestational diabetes risk calculator is an online application based on a logistical regression model. Input of maternal age, height, weight, racial origin, family history of diabetes, use of ovulation induction drugs, history of gestational diabetes and previous baby's birth weight and gestational age at delivery returns gestational diabetes risk in current pregnancy as a ratio. ${ }^{5}$

Objective of this study was to assess the feasibility of using the fetal medicine foundation gestational diabetes risk calculator to assess risk for gestational diabetes in a tertiary care hospital in coastal Karnataka.

\section{METHODS}

The study was conducted in A. J. Institute of Medical Sciences, Mangaluru between the months of April to June 2019. Data was collected from all patients who were admitted and underwent delivery during this time window.

\section{Inclusion criteria}

- All antenatal patients who have delivered in our Hospital in the time window of April to June 2019, with a recorded $1^{\text {st }}$ trimester weight, and evaluated for GDM.

\section{Exclusion criteria}

- Out born

- Antenatal patients with overt diabetes.

GDM was diagnosed as per MoHFW (Ministry of Health and Family Welfare, India) guidelines (2018), and an antenatal patient was said to be having gestational diabetes if she has an elevated OGTT more than 140 $\mathrm{mg} / \mathrm{dl}$ after a $75 \mathrm{~g}$ load irrespective of fasting state, or either an elevated fasting blood sugar more than $95 \mathrm{mg} / \mathrm{dl}$ or post prandial blood sugar more than $120 \mathrm{mg} / \mathrm{dl} .{ }^{1}$

\section{Data collected included the following}

- Maternal age

- Height

- Weight in $1^{\text {st }}$ trimester

- Racial origin

- Family history of diabetes

- Use of ovulation drugs

- History of gestational diabetes previous pregnancy

- Previous baby's birth weight and gestational age at delivery

The collected data was entered into the Fetal Medicine Foundation risk calculator WEBAPP (used with permission) which provided the risk for GDM as a ratio, with maximum probability being 1 in 2 (Figure 1, 2). The data collected was tabulated in a spreadsheet.

\section{RESULTS}

Incidence of GDM was $15.9 \%$ in the population. 56 of all the antenatal mothers met all the parameters of the inclusion and exclusion criteria. Out of these 12 were diagnosed as GDM.

At an arbitrary cut off of $1 / 80$ on the GDM risk calculator, the test predicted increased risk for 37 patients and decreased risk for 29 patients (Table 2). 


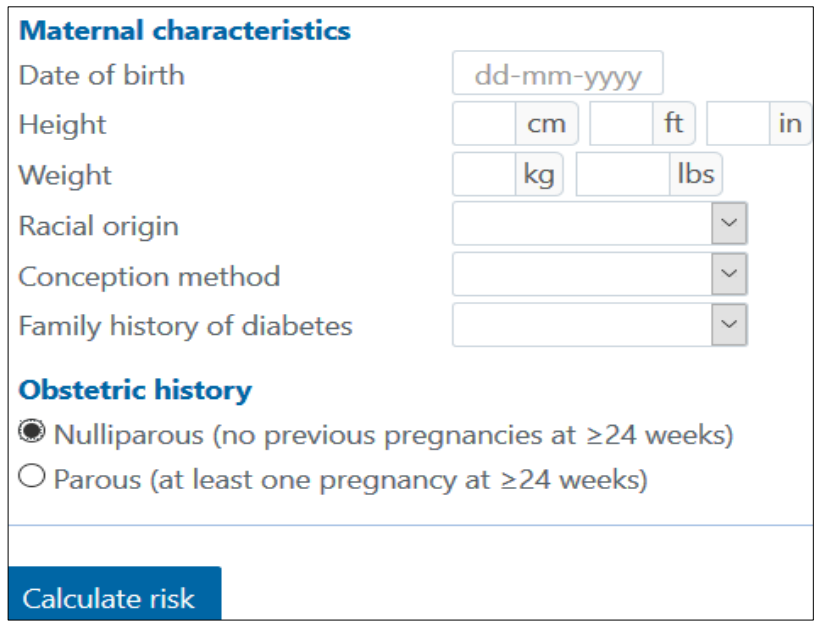

Figure 1: Parameters to be entered in the FMF GDM risk calculator for a primigravida.

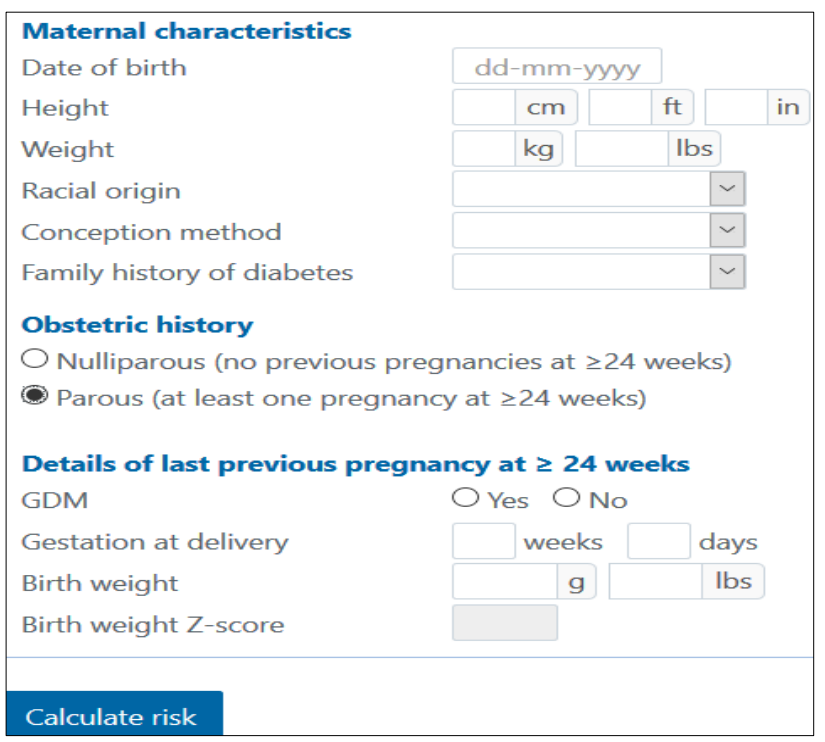

Figure 2: Parameters to be entered in the FMF GDM risk calculator for a multigravida.

The figures are screenshots from the web app from fetal medicine foundation's gestational diabetes risk calculator. After entering the mentioned values, the calculator provides the risk as a ratio.

Table 2: distribution of subjects based on diagnosis and outcome from the risk calculator.

\begin{tabular}{|ll|lc|}
\hline & $\begin{array}{l}\text { High } \\
\text { probability } \\
\text { of GDM }\end{array}$ & $\begin{array}{l}\text { Low } \\
\text { probability } \\
\text { of GDM }\end{array}$ & Total \\
\hline $\begin{array}{l}\text { Diagnosed as } \\
\text { GDM }\end{array}$ & 11 & 1 & $\mathbf{1 2}$ \\
\hline $\begin{array}{l}\text { Diagnosed as } \\
\text { non GDM }\end{array}$ & 16 & 28 & $\mathbf{4 4}$ \\
\hline Total & $\mathbf{2 7}$ & $\mathbf{2 9}$ & $\mathbf{5 6}$ \\
\hline
\end{tabular}

Consequently at $1 / 80$ cut off the GDM risk calculator had a sensitivity of $91.6 \%$ and specificity of $63.6 \%$. The negative predictive value was $96.5 \%$ and positive predictive value was $29.5 \%$. There was a false positive rate of $43.2 \%$.

Any result from the risk calculator more than $1 / 80$ was taken as high probability and less than $1 / 80$ taken as low probability.

\section{DISCUSSION}

Worldwide incidence of GDM is estimated to be about $10 \%$, with Asian ethnicities having a higher risk at an incidence of up to $17 \% .{ }^{11}$ The study presented with an incidence of $15.9 \%$ of patients having gestational diabetes. The study by Zheng et al showed an incidence of GDM in $12.8 \% .^{12}$ The study by Karacam et al, showed maximum incidence of $17.6 \%$ for GDM when detecting GDM based on advanced maternal age, BMI, weight gain in pregnancy, family history of diabetes, history of GDM or large baby in previous pregnancy. ${ }^{13}$

The fetal medicine foundation calculator considers all the risk factors for a better detection ratio, when compared to the individual factors in accordance to NICE guidelines. The calculator was created based on the study by Syngelaki et al. The multivariate model was created from 75,161 singleton pregnancies. The study demonstrated a sensitivity of $83.2 \%$ at a false positive rate of $40 \% .^{5}$ Comparatively, present study showed a sensitivity of $91.6 \%$ and specificity of $63.6 \%$ at a false positive rate of $43.2 \%$. Similarly, a population study by Caliskan et al, to determine effectiveness of a risk factor based scoring for GDM had a sensitivity of $71 \%$ at an FPR of $40 \% .{ }^{14}$ Nanda et al, reported detection rates of GDM at $61.6 \%$ at $20 \%$ false positive rate based on maternal age, body mass index, racial origin, previous history of GDM and macrosomic neonate, and an improved detection rate of $78 \%$ at a false positive rate of $40 \% .^{15}$

In present study, $42 \%$ of the patients with GDM were diagnosed in the third trimester. Similarly, in the study by Kaira et al, $51.2 \%$ of GDM mothers was detected in third trimester. ${ }^{16}$ Naylor et al in their prediction model showed a detection rate of $67 \%$, with false positive rate $40 \%$ when using a logistic regression model. ${ }^{17}$ Similarly, at $40 \%$ false positive rate, Teede et al, demonstrated a detection rate of $77 \%$ in their GDM risk prediction tool. ${ }^{18}$ Van Leeuwen et al, in their study using a prediction model, detected $79 \%$ of GDM at a false positive rate for $40 \%{ }^{19}$

\section{CONCLUSION}

The fetal medicine foundation GDM risk calculator will prove to be an invaluable tool to predict high risk patients who need closer monitoring of blood glucose into the third trimester. 


\section{ACKNOWLEDGMENTS}

Authors would like to thank fetal medicine foundation, for giving permission of use of their risk prediction software for the study.

\section{Funding: No funding sources}

Conflict of interest: None declared

Ethical approval: The study was approved by the Institutional Ethics Committee

\section{REFERENCES}

1. National Health Mission Ministry of Health and Family Welfare, "diagnosis and management of gestational diabetes mellitus". Natl Heal Mission Minist Heal Fam Welf. 2018;1-2.

2. Farrar D, Duley L, Dowswell T, Lawlor DA. Different strategies for diagnosing gestational diabetes to improve maternal and infant health. Cochrane Database Syst Rev. 2017;8:2017.

3. KC K, Shakya S, Zhang H. Gestational diabetes mellitus and macrosomia: a literature review. Ann Nutr Metab. 2015;66(2):14-20.

4. Mishra S, Bhadoria A, Kishore S, Kumar R. Gestational diabetes mellitus 2018 guidelines: An update. J Fam Med Prim Care. 2018;7(6):1169-72.

5. Syngelaki A, Pastides A, Kotecha R, Wright A, Akolekar R, Nicolaides KH. First-trimester screening for gestational diabetes mellitus based on maternal characteristics and history. Fetal Diagn Ther. 2015;38(1):14-21.

6. World Health Organization. Report of a WHO/IDF Consultation. Definition and diagnosis of diabetes mellitus and intermediate hyperglycemia. Available at: https://www.who.int/diabetes/publications/ diagnosis_diabetes2006/en. Accessed $15^{\text {th }}$ January 2020.

7. Rani PR, Begum J. Screening and diagnosis of gestational diabetes mellitus, where do we stand. J Clin Diagnostic Res. 2016;10(4):QE01-QE04.

8. Cheng AYY, Cheng AYY. Canadian Diabetes Association 2013 clinical practice guidelines for the prevention and management of diabetes in Canada. Can J Diabetes. 2013;37:S1-S3.

9. International Association of Diabetes and Pregnancy Study Groups Consensus Panel. International association of diabetes and pregnancy study groups recommendations on the diagnosis and classification of hyperglycemia in pregnancy. Diabetes Care. 2010;33(3):676-82.
10. Seshiah V, Balaji V, Balaji MS, Sekar A, Sanjeevi $\mathrm{CB}$, Green A. One step procedure for screening and diagnosis of gestational diabetes mellitus. J Obs Gynecol India. 2005;55(6):525-9.

11. Xiang AH, Li BH, Black MH, Sacks DA, Buchanan TA, Jacobsen SJ, Lawrence JM. Racial and ethnic disparities in diabetes risk after gestational diabetes mellitus. Diabetol. 2011;54(12):3016-21.

12. Zheng T, Ye W, Wang X, Li X, Zhang J, Little J, et al. A simple model to predict risk of gestational diabetes mellitus from 8 to 20 weeks of gestation in Chinese women. BMC Preg Childbirth. 2019;19(1):252.

13. Karaçam Z, Çellik D. The prevalence and risk factors of gestational diabetes mellitus in Turkey: a systematic review and meta-analysis. J Matern Neonatal Med. 2019:1-11.

14. Caliskan E, Kayikcioglu F, Ozturk N, Koc S, Haberal A. A population-based risk factor scoring will decrease unnecessary testing for the diagnosis of gestational diabetes mellitus. Acta Obstet Gynecol. Scand. 2004;83(6):524-30.

15. Nanda S, Savvidou M, Syngelaki A, Akolekar R, Nicolaides KH. Prediction of gestational diabetes mellitus by maternal factors and biomarkers at 11 to 13 weeks. Prenat Diagn. 2011;31(2):135-41.

16. Kaira S. P-68 'Late onset' gestational diabetes mellitus (LO-GDM): distinct cohort. Diabetes Res. Clin Pract. 2008;79:S80.

17. Naylor CD, Sermer M, Chen E, Farine D. Selective screening for gestational diabetes mellitus. N Engl J Med. 1997;337(22):1591-6.

18. Teede HJ, Harrison CL, The WT, Paul E, Allan CA. Gestational diabetes: development of an early risk prediction tool to facilitate opportunities for prevention. Aust New Zeal J Obstet Gynaecol. 2011;51(6):499-504.

19. Van Leeuwen M, Opmeer BC, Zweers EJ, Van Ballegooie E, Ter Brugge HG, De Valk HW, et al. Estimating the risk of gestational diabetes mellitus: a clinical prediction model based on patient characteristics and medical history. An Inter J Obstet Gynaecol. 2010;117(1):69-75.

Cite this article as: Ganiga $P$, Subhash VV. Retrospective study on assessment of risk for gestational diabetes using fetal medicine foundation's gestational diabetes risk assessment calculator in a tertiary care hospital in coastal Karnataka, India. Int J Reprod Contracept Obstet Gynecol 2020;9:1324-7. 